Burak Yıldız

Bekir Şener

Ahmet Yurtseven

Toru Katayama

http://dx.doi.org/10.21278/brod70201

\title{
NUMERICAL AND EXPERIMENTAL CALCULATION OF ROLL AMPLITUDE EFFECT ON ROLL DAMPING
}

\author{
UDC 629.5.015.1:629.5.017.22
}

Original scientific paper

\begin{abstract}
Summary
Roll motion is still a challenging problem in naval architecture and an adequate prediction of this physical phenomenon is important because of its undesirable effects such as capsizing. There are several methods using linear potential theory to predict roll motion, such as strip method, however, the accuracy of the calculated results lag behind the accuracy of other degrees of freedom due to viscosity. Viscosity have an important effect on roll damping, especially near resonance, and as it is known, it is not included in potential flow methods. Vortex shedding is the main physical phenomena in viscous damping of the roll motion and it affects the flow velocity around the bilge. This may lead to pressure increase or decrease on the hull. In the present study, roll damping of a forced rolling hull with bilge keels at different roll amplitudes was calculated numerically by using an Unsteady Reynolds-averaged NavierStokes (URANS) solver. For the purpose of validation, forced roll experiments were carried out and the results were plotted next to numerical results. The generated vortices around the hull and bilge keel were observed in the URANS calculations. In the case of large roll amplitude motion, the vortex shedding from the bilge keel interacts with the free surface and leads to decrease on roll damping.
\end{abstract}

Key words: Roll damping; bilge keel; large amplitude, vortex shedding, computational fluid dynamics

\section{Introduction}

Roll motion is the oscillatory motion of a vessel along its longitudinal axis. As the transverse loads are governed by roll motion, large-amplitude roll motions compromise the stability of a floating body and also affects structural integrity, crew and passenger comfort, machinery operations and ultimately the safety of a vessel. If the roll motion can be predicted at an early design stages, the vessel can be designed to withstand with the imposed dynamic motions in response to the environmental loads. However, prediction of roll damping has always been a challenging task for naval architects. As indicated above, accurate estimation of the roll motion is of great importance; underestimation can potentially cause disasters while 
its overestimation results in a commercially unviable design that leads am increase of the weight and limits operability of the floating body.

Ship motions are mainly damped by the generation of surface waves which radiate from the ship in most cases. Hence the viscous damping components can usually be ignored and potential flow methods can be used to sufficiently simulate the motions [1]. However, this is not valid for roll motion. Linear radiation damping is the part of the roll damping caused by radiated surface waves and can be calculated using linear potential theory. However, viscous effects like flow separation, vortex shedding cannot be computed in potential flow methods.

In addition, ship appendages can have a noticeable effect on roll damping. Especially bilge keels are the most simple and effective appendages creating additional damping as a result of flow separation from their edges. Bilge keels provide a vortex around the body which increases the viscous contribution to the total damping. The generated vortices mitigate the roll motion by transferring energy from the ship to the surrounding fluid.

Many researchers have studied the viscous roll damping prediction, e.g. Ikeda et al. [2, 3, 4] and Himeno [5]. The recommended procedures for roll damping estimation are empirical, based on model tests, full-scale tests or from a database developed from model tests. Considering the relative simplicity of these methods, they perform reasonably well in most cases especially for conventional hull shapes and bilge keel sizes. However, Ikeda's method is typically valid only for small roll motions which were only performed for roll amplitudes up to $15 \mathrm{deg}$ and later extended to $20 \mathrm{deg}$. Several improvements of the method have been proposed in recent years, both to make it simpler [6] and to add the capability for handling special cases such as shallow drafts [7] and high-speed vessels [8, 9]. In the present paper, the effects of coming close the bilge keel to the free surface have been also investigated which is usually neglected.

Model experiments are the most common and accurate way for roll damping calculations. However, they are time-consuming and expensive to investigate lots of different options, such as the effects of different bilge keel shapes and positions or different locations of center of gravity on roll damping. Alternatively, in recent years, computational fluid dynamics (CFD) tools have been applied for solving the ship roll motion extensively. Since one of the major component of roll damping comes from the viscous and eddy-making effects of the flow, CFD based Unsteady RANS solvers have the potential to produce superior roll damping predictions compared to existing methods since the effects due to viscosity, creation of vorticity in the boundary layer, vortex shedding and turbulence are naturally included in the calculations. The advantages, such as low cost and fast computational time compared to experiments, lead researchers to use CFD for the estimation of roll damping.

URANS-equation methods have been used primarily by Yeung and Ananthakrishnan [10] to solve the nonlinear viscous-flow problem associated with heaving motion of a twodimensional floating cylinder. Their work has led to the use of URANS-equation methods in the analysis of roll motion; several researchers used URANS solvers to study the flow around two-dimensional oscillating cylinders $[11,12,13]$. Bassler [14] realized forced roll test and CFD simulations to investigate the effects of hull and bilge keel geometry on damping of large amplitude roll motion. Avalos et al. [15] carried out CFD simulations with their own two-dimensional Navier-Stokes solver for free roll decay of FPSO. They performed simulations with and without bilge keels and compared results with the experiments carried out by Oliviera and Fernandes [16]. They presented that vortex size and roll damping depends on the amplitude of roll motion and the width of bilge keel. By using a commercial CFD code, Van Kampen [17] revealed a practical method to evaluate roll damping and motions of an FPSO. He conducted simulations with different type bilge keels and riser balconies in waves and used results to modify traditional Ikeda's method. Irkal et al. [18] investigated the 
best configuration of a bilge keel to reduce roll motion with numerical simulations using a commercial RANSE solver. As a result of the simulations, they obtained velocity and vorticity distributions around the bilge keel alternatives and validated with PIV measurements. The effect of the shallow draft on roll damping was studied by Yildiz et al. [19] by using URANS method. They performed two-dimensional roll damping calculations for a forced rolling S60 midsection with bilge keels and validated the results with experiments. They presented that Ikeda's method overestimates at shallow draft conditions due to not considering the interaction between free surface and bilge keel.

Ommani et al. [20] performed a two-dimensional numerical study on a horizontal, circular cylinder fitted with one bilge keel forced to rotate harmonically around its axis. They used a Navier-Stokes solver based on the Finite Volume Method and simplified the problem by neglecting the influence of nonlinear advection terms and viscous stresses in the freesurface zone. Three different drafts and one fully submerged case far away from the free surface were considered in their work and three different bilge keel shape were used. They validated the numerical results with experimental data and presented that the simplified modeling and relatively coarse mesh could result in accurate prediction both in terms of forces on the bilge keel and the pressure distribution on the hull surface. Y1ldiz and Katayama [21] also used a RANS solver to carry out CFD simulations of roll damping for a twodimensional model of a ship with bilge keels at the various draft. They performed experiments to validate the numerical calculations and investigated the generated vortices and vortex shedding numerically at deep and shallow draft conditions. Ikeda's method gives a constant value for each draft condition, however they observed that the core and strength of the vortex decrease when the bilge keel come close to the free surface at the shallow draft.

Although there have been many studies on roll damping estimation by using experiments or CFD methods, there is still a critical need for the development of methods for predicting large amplitude roll damping of ships with appendages. In the present study, the effect of roll amplitude on roll damping was investigated numerically and experimentally. The forced roll simulations were carried out to calculate the roll damping moment. The vorticity generation around the hull was visualized by using numerical solver. The effect of vortex shedding and free surface interaction were investigated at different roll amplitudes. It was observed that the roll damping decreased when the bilge keels come close to the free surface at large roll amplitudes. Numerical results showed good accuracy with the experimental results. The numerical and experimental uncertainty analysis have also been performed to endorse the accuracy of the results.

\section{Determination of the roll damping coefficient}

Roll damping is obtained by analysis of the measured roll moment and roll motion from experimental and numerical forced roll test. The roll angle $\emptyset(\mathrm{t})$ is forced by;

$$
\emptyset(t)=f(t) \emptyset_{0} \sin \omega t
$$

The equation of one-degree-of-freedom (1-DoF) forced roll motion is given in Eq. 2.

$$
\left(I_{\emptyset \emptyset}+a_{\emptyset \emptyset}\right) \emptyset^{n}+B\left(\emptyset, \emptyset^{\prime}\right)+C(\emptyset)=M_{E}(t)
$$

where $I_{\varnothing \varnothing}$ is mass moment of inertia, $a_{\varnothing \varnothing}$ is the added mass moment of inertia for roll motion, $B\left(\emptyset, \emptyset^{\prime}\right)$ is the damping moment, $C(\emptyset)$ is the restoring moment and $M_{E}(t)$ is the time history of the measured or computed moments and it is fitted by Eq. 3;

$$
M_{E}(t)=M_{0} \sin (\omega t+\varepsilon)
$$


by applying the Fourier analysis which is used as an equivalent linearization method for energy, $M_{0}$ is the roll amplitude and $\varepsilon$ indicates the phase angle between the roll angle and the roll moment. Time history of the moments is obtained by experiments or CFD simulations, then $M_{0}$ and $\varepsilon$ can be calculated by applying Fourier analysis to the time history of moments. The roll damping coefficient can be expressed as follow:

$$
B_{44}=\frac{M_{0} \sin (s)}{\emptyset_{0} \omega}
$$

Finally, non-dimensional representations of the damping coefficient is found as follow:

$$
\widehat{B}_{44}=\frac{B_{44}}{\rho \nabla B_{W L}^{2}} \sqrt{\frac{B_{W L}}{2 g}}
$$

\subsection{Experimental investigation}

The forced roll tests were carried out to obtain the roll damping coefficients experimentally. A two-dimensional (2D) midship section model with attached bilge keels was used for calculations. Table 1 shows the principal particulars of the model with bilge keels.

Table 1 Principle particulars of 2D model

\begin{tabular}{|l|l|}
\hline Length, L (m) & 0.80 \\
\hline Breadth, B (m) & 0.237 \\
\hline Depth, D (m) & 0.145 \\
\hline Center of gravity, KG (m) & 0.072 \\
\hline Block coefficient, $\mathrm{C}_{\mathrm{B}}$ & 0.8 \\
\hline Bilge radius & 0.035 \\
\hline Length x Breadth (Bilge keel) $(\mathrm{m})$ & $0.80 \times 0.01$ \\
\hline
\end{tabular}

During the forced roll tests, the model was only allowed to roll motion and the other motions were restricted. The sinusoidal 1-DoF forced roll oscillations were applied to the 2D model and the roll moments were measured. Fig. 1 shows the 2D model attached to the forced roll mechanism.
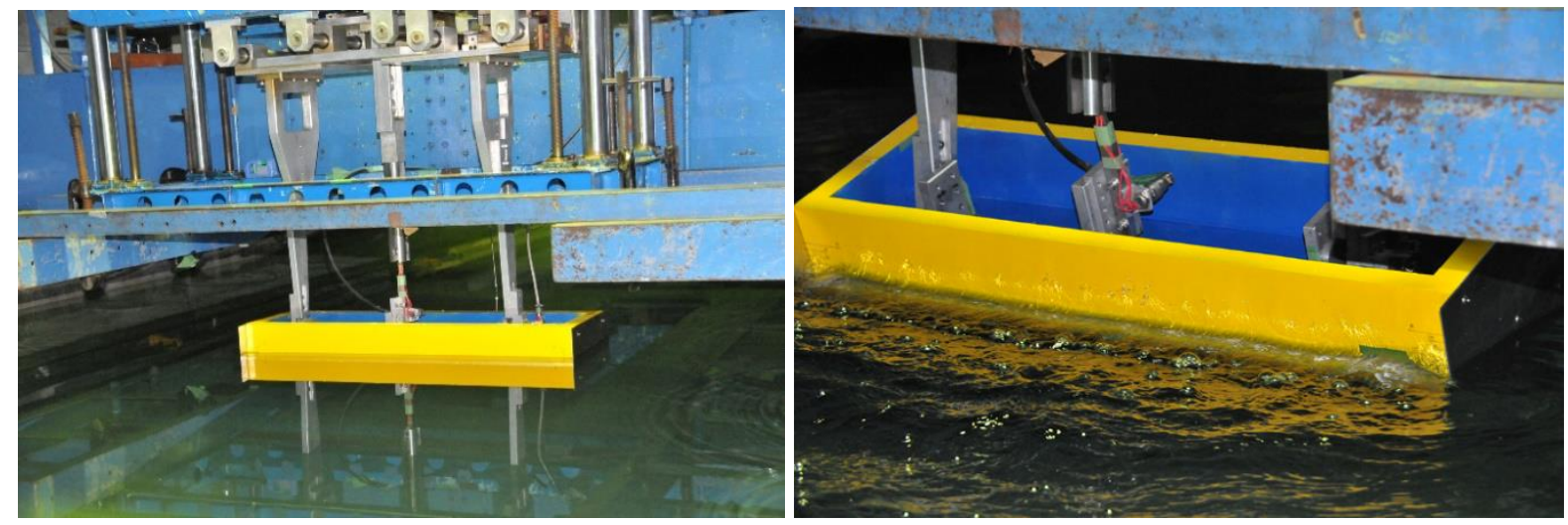

Fig. 1 The 2D midship model attached forced roll mechanism 
The single-degree-of-freedom strain gage sensors were embedded into the arms and used to obtain the moment measurements (Fig. 2).

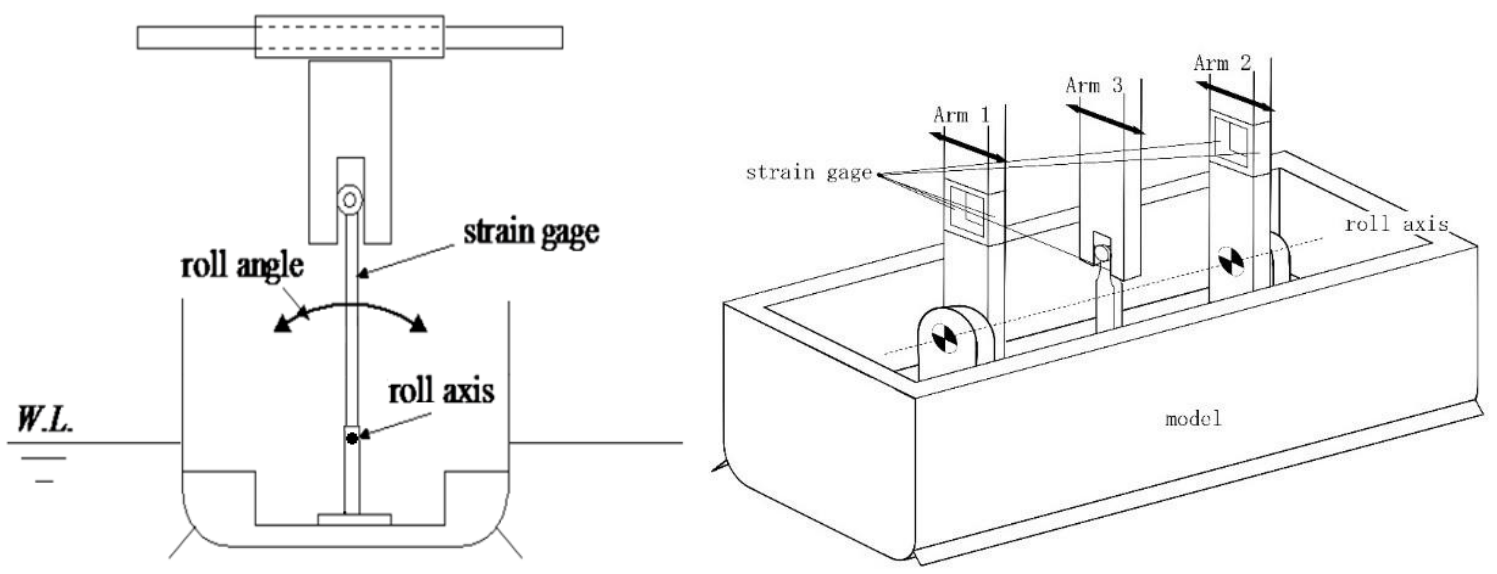

Fig. 2 Schematic view of forced roll mechanism

The experiments were conducted with combinations of roll amplitudes to show the effect of roll amplitude on roll damping (Table 2). The roll moments were measured for different roll amplitudes and the roll damping coefficients were calculated.

Table 2 Test conditions

\begin{tabular}{|l|l|}
\hline Fn & 0.0 \\
\hline Roll amplitude, $\emptyset(\mathrm{deg})$ & $8.59,11.38,14.38,20.0,27.27$ \\
\hline Roll period, T (s) & 1.2 \\
\hline Draft, d (m) & 0.042 \\
\hline
\end{tabular}

The uncertainty of the test device was checked and the results were published in the previous paper by the authors. The detailed information about the uncertainty analysis can be found in [21].

\subsection{CFD simulations}

\subsubsection{Numerical settings}

The flow around the oscillating body was solved numerically by a commercial URANS solver. The numerical 2D model was forced to the sinusoidal roll motion at a fixed axis as it was applied in the experiments. The generated numerical geometry and mesh around the 2D hull is shown in Fig. 3. The mesh size around the bilge keels should be small enough to capture the generated vortices accurately as it is shown in Fig. 4. The volume of fluid (VOF) method was used to solve the multiphase flows with the free surface at the air-water interface. The k- $\varepsilon$ turbulence model was selected for the calculations. The top boundary of the computational domain was defined as open to atmospheric pressure and the bottom boundary was selected as wall, both ends were defined as outflow boundary. The roll moments were calculated at the same conditions with experiments and the roll damping coefficients were obtained numerically. 


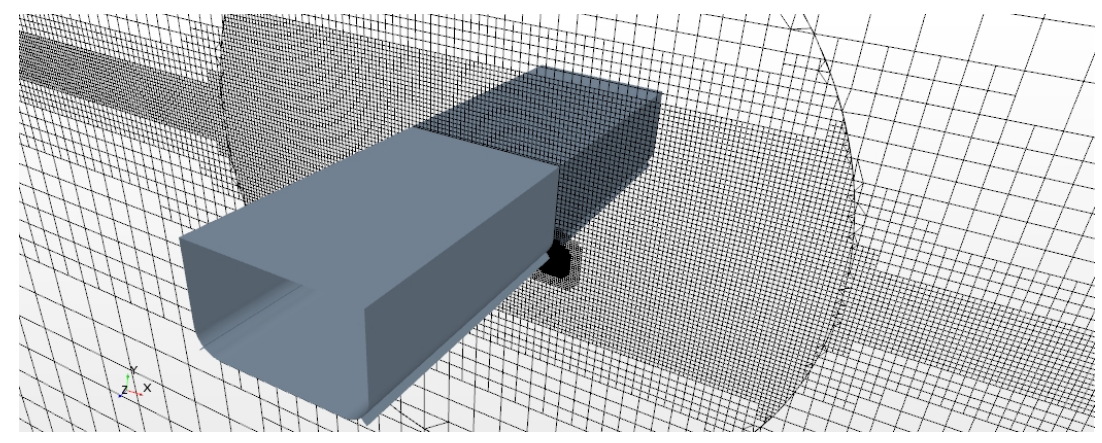

Fig. 3 The geometry and computational mesh

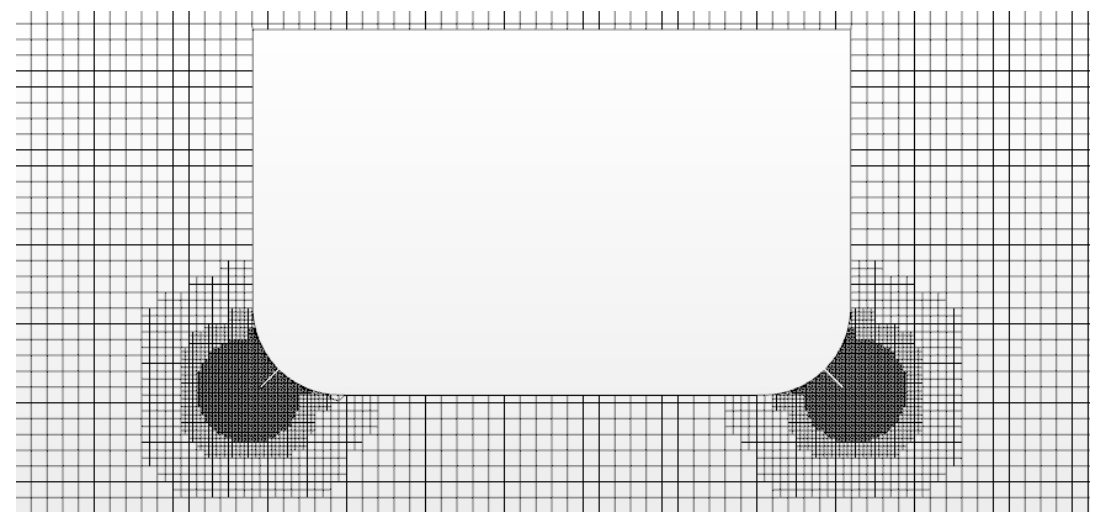

Fig. 4 Generated mesh around the hull and bilge keels

\subsubsection{Numerical verification study}

The verification study has been made via Grid Convergence Method (GCI). This method, which depends on Richardson Extrapolation, was introduced by Roache [22] and then it was used in numerous studies. In the present study, the procedure developed by Celik et al. [23] was used for verification study. Grid spacing and time step size, two of the main sources of uncertainty, were selected for verification study and the other sources were neglected. The time step size and grid resolution were refined systematically with constant refinement factor $\sqrt{ } 2$ as usually selected for verification. Three mesh cases; coarse (a) 3.00 million of cells, medium (b) 4.24 million of cells, and fine mesh (c) 6.00 million of cells, are shown in Fig. 5. It should be noted that in grid spacing verification study, the refinements were implemented only the overset region. The time-step convergence study was conducted on the finest grid (Case $\mathrm{C}$ ) by systematically refined time steps with refinement ratio equal to $\sqrt{2}$, i.e. $0.005 \mathrm{~s}, 0.007 \mathrm{~s}$ and $0.01 \mathrm{~s}$. It should also be noted that in the grid spacing verification study time-step was selected as medium time step which equals to $0.007 \mathrm{~s}$. However, in the time step convergence study, the grid spacing was selected fine grid.

For verification of each source (time step \& grid spacing), three solutions were considered and only one source of uncertainty was changed. 


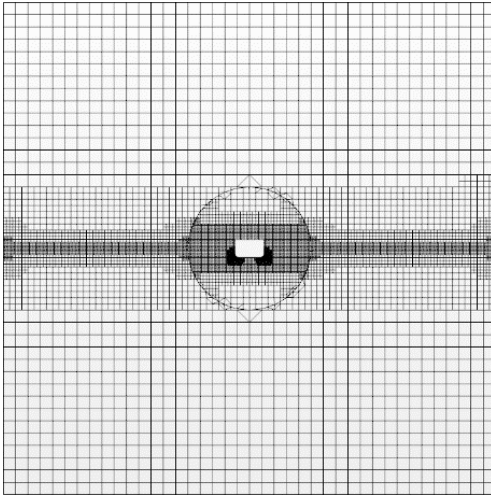

(a)

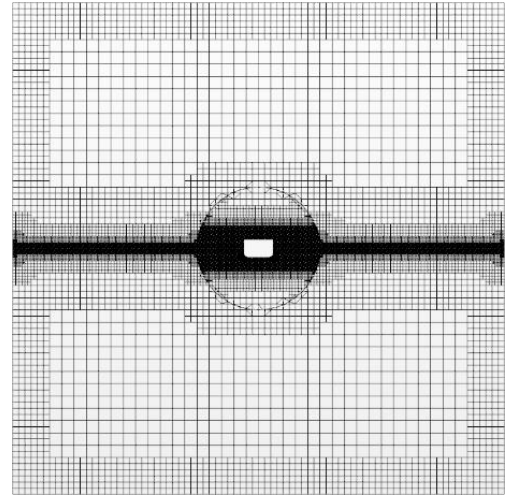

(b)

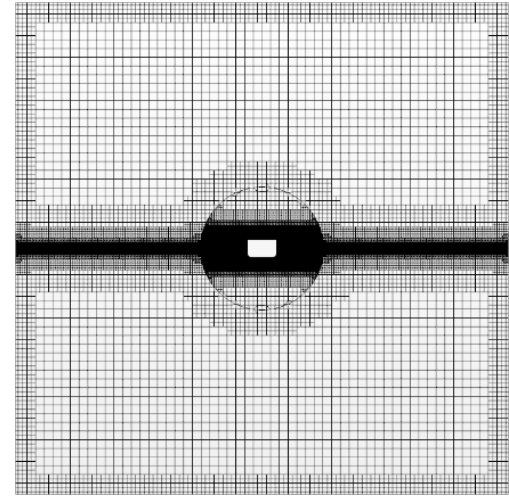

(c)

Fig. 5 Used mesh cases: (a) coarse case, (b) medium case, and (c) fine case

For instance, the time step size was kept constant while grid spacing was being refined systematically. The methodology applied in this paper can be briefly expressed as follows [23]. The difference between the solution scalars $(\varepsilon)$ should be determined by Equation (8):

$$
\varepsilon_{21}=\varphi_{2}-\varphi_{1} \quad \varepsilon_{32}=\varphi_{3}-\varphi_{2}
$$

In these equations $\varphi_{1}, \varphi_{2}$ and ${ }^{\varphi_{3}}$ refer solution of course, medium and fine mesh grid or timestep size, respectively. Convergence condition of the numerical study can be calculated by Equation (9):

$$
\mathrm{R}=\frac{\varepsilon_{21}}{\varepsilon_{32}}
$$

The convergence condition has to be between 0 and 1 to monotonic convergence [24]. The apparent order of p can be found by Equation (10) [23]:

$$
\mathrm{p}=\frac{\ln || \varepsilon_{32} / \varepsilon_{21}|+\mathrm{q}|}{\ln \left(\mathrm{r}_{21}\right)}
$$

Here,

$$
\begin{aligned}
& \mathrm{q}=\ln \left(\frac{\mathrm{r}_{21}-\mathrm{s}}{\mathrm{r}_{32}-\mathrm{s}}\right) \\
& \mathrm{s}=\operatorname{sgn}\left(\varepsilon_{32} / \varepsilon_{21}\right)
\end{aligned}
$$

The extrapolated value is:

$$
\varphi_{\text {ext }}^{21}=\left(\mathrm{r}^{\mathrm{p}} \varphi_{1}-\varphi_{2}\right) /\left(\mathrm{r}^{\mathrm{p}}-1\right)
$$

The approximate relative error and extrapolated relative error are:

$$
\mathrm{e}_{\mathrm{a}}^{21}=\left|\frac{\varphi_{1}-\varphi_{2}}{\varphi_{1}}\right| \quad \mathrm{e}_{\mathrm{ext}}^{21}=\left|\frac{\varphi_{\mathrm{ext}}^{12}-\varphi_{1}}{\varphi_{\mathrm{ext}}^{12}}\right|
$$


Finally, the GCI index is calculated by:

$$
\mathrm{GCI}_{\text {fine }}^{21}=\frac{1.25 \mathrm{e}_{\mathrm{a}}^{21}}{\mathrm{r}_{21}^{p}-1}
$$

Table 3 Verification study

\begin{tabular}{|l|c|c|}
\hline & Grid Convergence & Time Step Convergence \\
\hline$\varphi_{1}$ & 0.03777 & 0.05267 \\
\hline$\varphi_{2}$ & 0.03919 & 0.04056 \\
\hline$\varphi_{3}$ & 0.03952 & 0.03952 \\
\hline $\mathrm{R}$ & 0.185 & 0.079 \\
\hline$\% \mathrm{GCI}_{\text {FINE }}$ & 0.232 & 0.275 \\
\hline
\end{tabular}

The uncertainty values of the roll damping coefficients are given in Table 3 . The convergence was achieved at both grid and time-step uncertainty and percentages are at applicable levels for both cases.

\section{Results and discussion}

\subsection{Roll moments and roll damping coefficients}

CFD computations have been carried out for the hull at five different roll amplitude values and results have been compared with experimental results. The moments acting on the hull and bilge keels were computed separately while the hull was forced to the roll motion. Fig. 6 and 7 show the total (hull + bilge keel) moments and bilge keel moments obtained from numerical analyses at different roll amplitudes. As it is shown on the Fig.6, the total moment increases when the roll amplitude increases. However, the bilge keel moment decreases at the point where the bilge keel interacts with the free surface. This effect cannot be seen in the total moment figure because the damping moment is a small portion of total moment. The effect of free surface interaction can be seen in Fig. 7. The bilge keel moment increases until $20 \mathrm{deg}$. but decreases at $27.27 \mathrm{deg}$. where bilge keels come closer to the free surface.

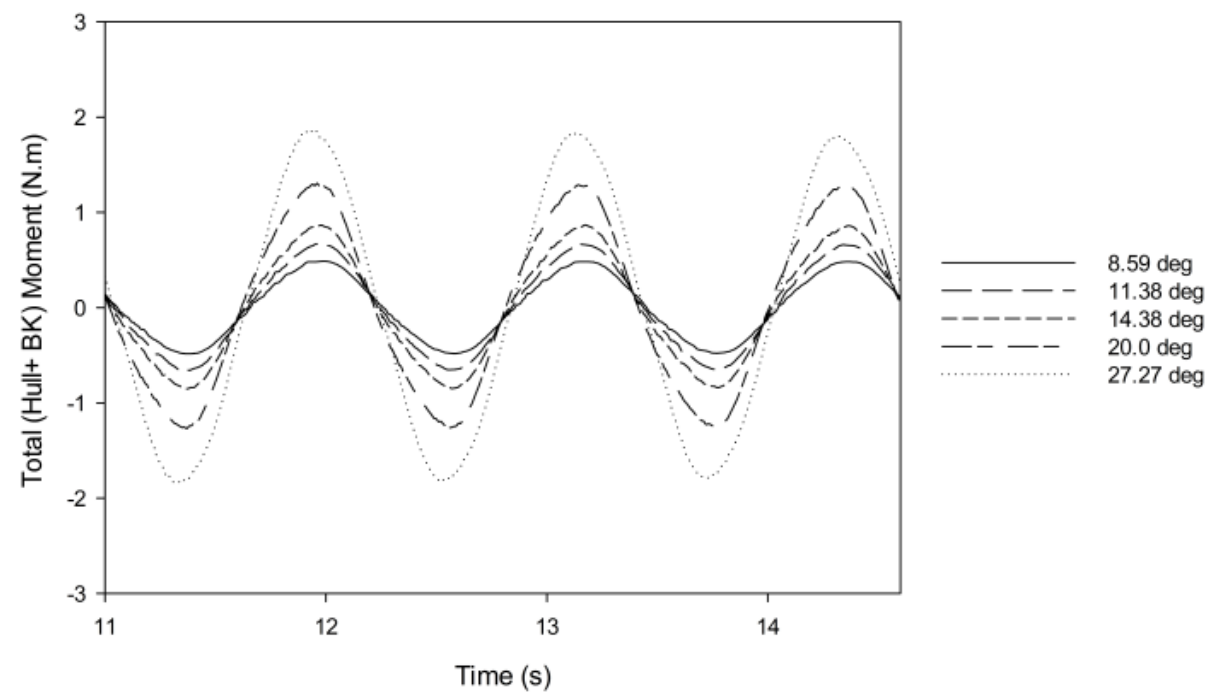

Fig. 6 Time history of total (Hull + BK) numerical moment for different roll amplitudes 


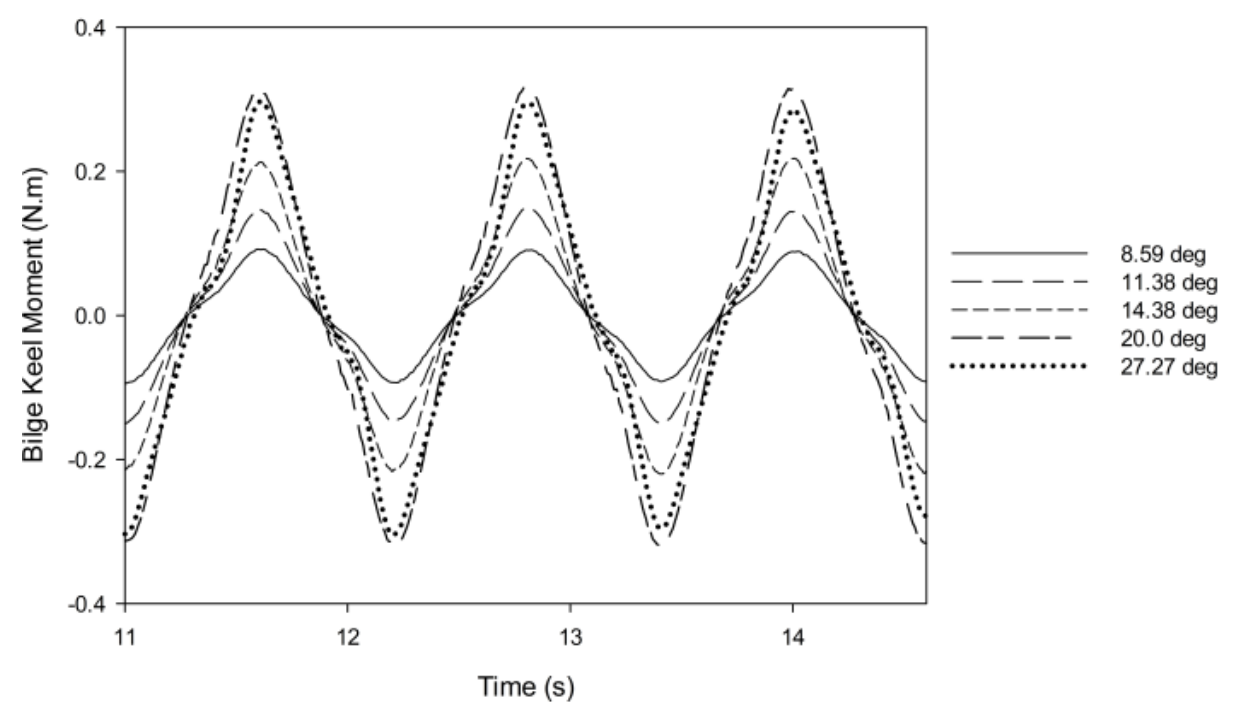

Fig. 7 Time history of the numerical bilge-keel moment for different roll amplitudes

The roll damping coefficients have been calculated numerically and were obtained experimentally by using moments acting on the hull and bilge keels. Fig. 8 shows numerical and experimental non-dimensional roll damping coefficients at different roll angles. A good agreement between numerical results and experiments at each roll amplitude was observed. The roll damping increased from small to moderate roll amplitudes and it decreased at the largest amplitude. When the roll amplitude increases, the bilge keel come close to the free surface and this cause the vorticity around the bilge keels vortex shedding which affect the force acting on the bilge keels and the roll damping.

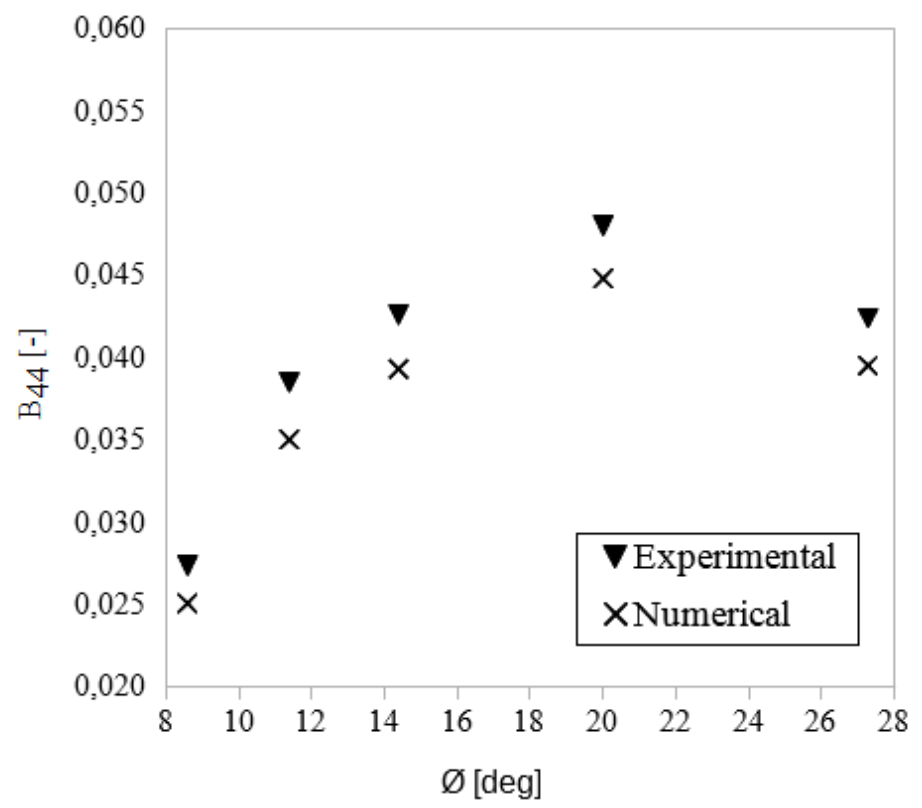

Fig. 8 Numerical and experimental roll damping coefficients at different roll angles

The bilge keels provide the largest contribution to energy dissipation [5]. However, bilge keels are more effective when they are fully submerged, typically only for small and moderate roll motion, and at lower speeds $[4,5]$. According to the results of numerical 
analyses, as shown in Fig. 9, the bilge keel roll damping shows the same tendency as the total roll damping to decreases at large amplitudes that the bilge keel come close to the free surface. Also, roll damping contribution to the total roll damping decreases when the bilge keel comes closer to the free surface. Fig.10 shows the percentage of the bilge keel damping on total roll damping obtained from numerical results at different roll amplitudes. The dark parts show the bilge keel damping contribution. At the large roll amplitude, the bilge keel contribution is less as it was mentioned by Ikeda [4]. In the previous paper [25], authors showed the comparison of roll damping coefficients calculated with numerical solver and Ikeda's estimation method. Ikeda's method overestimated the roll damping value at large roll amplitudes because the method does not account for the free surface effect.

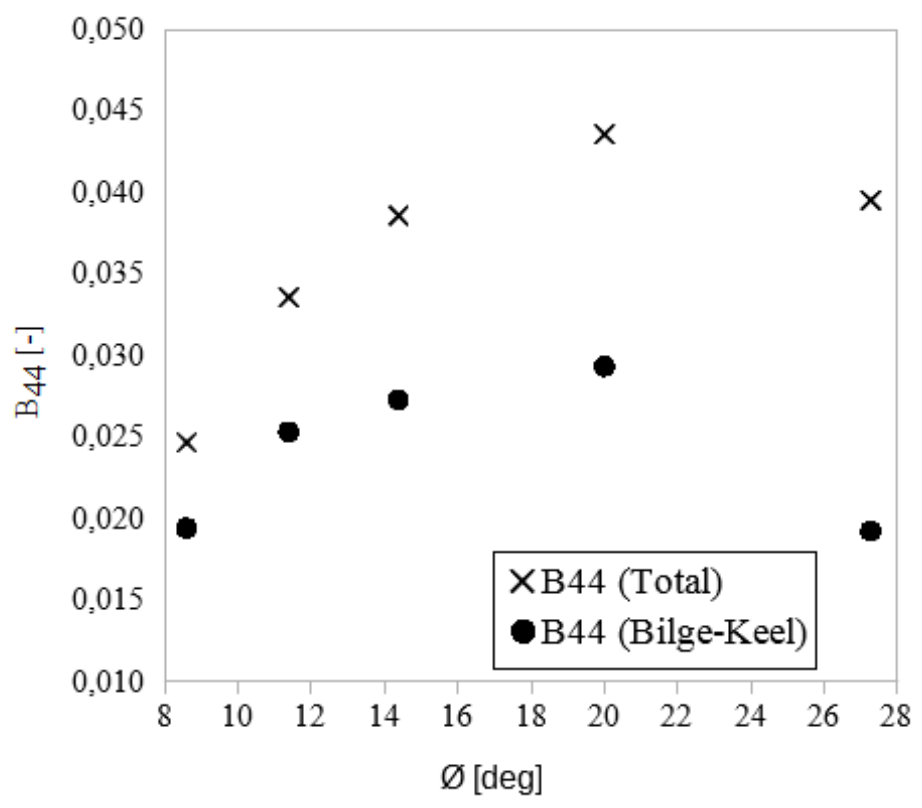

Fig. 9 Numerical bilge-keel damping and total roll damping coefficients at different roll angles

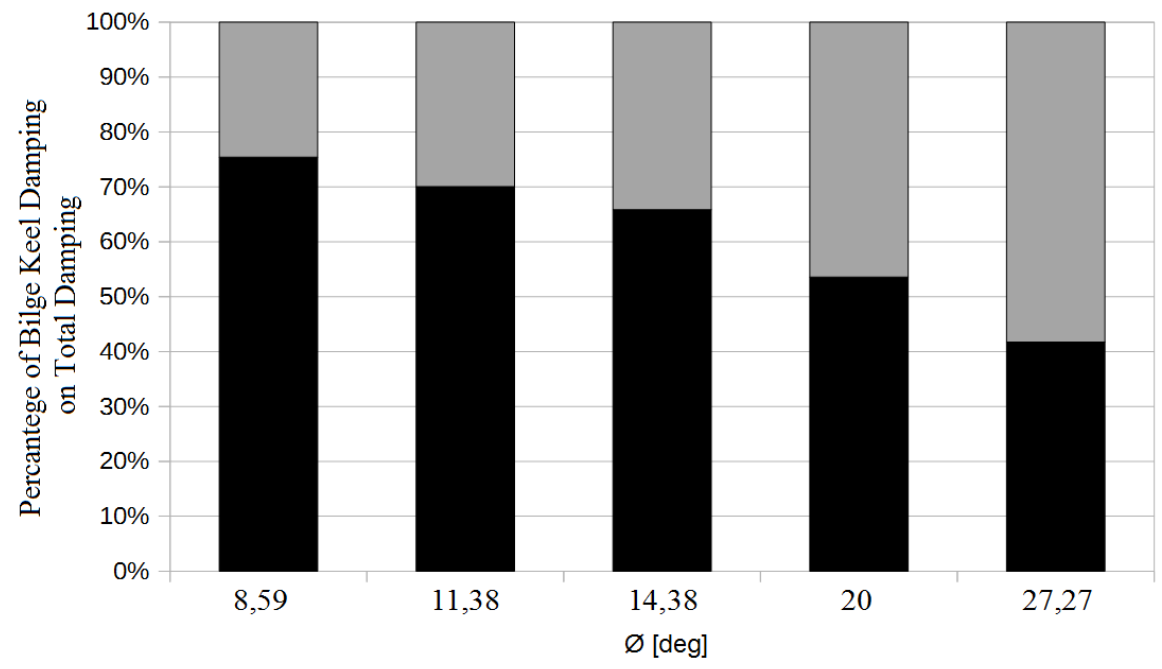

Fig. 10 Percentage of the numerical bilge-keel damping on the total roll damping 


\subsection{Generation of the vortices around the hull with bilge keels}

The generated vortices from the bilge keel causes to changes in the bilge keel force and so the roll damping. Vortex shedding is the main physical phenomena involved in the viscous damping and it affects the flow velocity around the body that may lead to changes in the pressure gradients on the hull. To investigate the effect of the roll amplitude on the roll damping, the generation of vortices near the bilge-keels were investigated numerically for different roll amplitudes. The blue colour in the figures denotes negative (clockwise) vorticity while the red colour denotes positive (counter-clockwise) vorticity and the vorticity (1/s) scale is same for all figures, ranging from -50 to 50 . Fig. 11 shows the generated vortices around the hull and bilge keels at a 8.59 deg roll amplitude and a 20.0 deg amplitude. As shown, the size and core of the vorticity increase with increasing the roll amplitude. This explains how the roll damping increases when the roll amplitude increases. However, the roll damping decreases when the roll amplitude is $27.27 \mathrm{deg}$. As mentioned before, the bilge keel comes closer to the free surface at this position. The vorticity generation around the hull were compared for different roll amplitudes to investigate the vortex shedding and free surface interaction on roll damping.

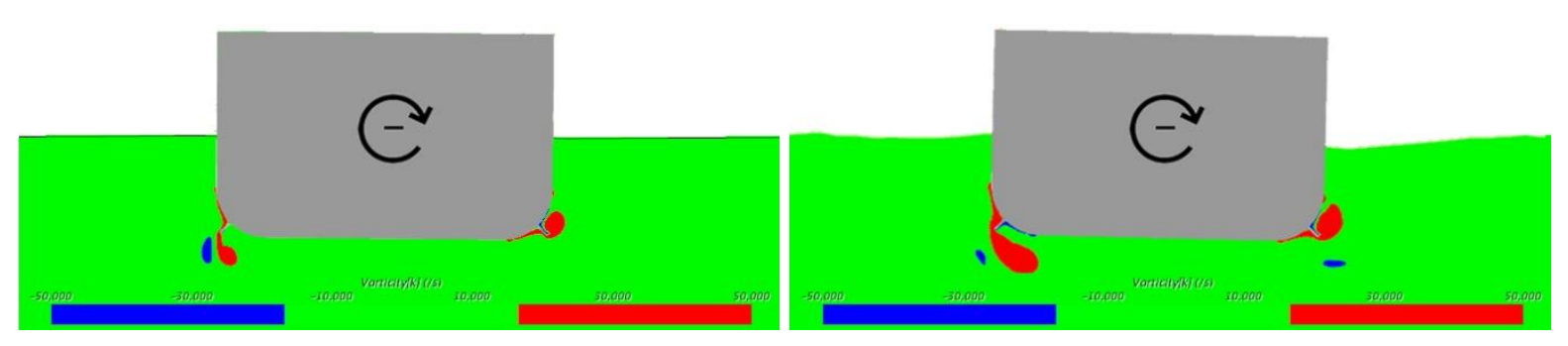

Fig. 11 Generation of vortices around hull at max roll speed (left: $8.59 \mathrm{deg}$, right: $20.0 \mathrm{deg}$ )

Vorticities around the bilge keel are shown in Fig. 12 a and b, for roll amplitudes of 20 deg and $27.27 \mathrm{deg}$, respectively. The vortices are shown for the half oscillation period for both conditions. As it can be seen in the Fig. 12, the vortices are strongest when the hull reaches its maximum roll velocity. The generated positive vortices start to shed while the hull is rolling. At the maximum roll amplitude, where the roll speed is zero, the positive shed vortices start to dissipate after the hull reaches the maximum roll amplitude. At this point, roll direction changes and negative vortex starts to occur from the tip of the bilge keels and grows gradually. The previously generated positive vortex interacts with the new generated positive vortex and dissipates into the surrounding fluid while the body reaches the maximum roll velocity. The more intense negative vortex is dragging the positive vortex that is less intense, as it has been also shown in Avalos et al. [15]. As the hull rolls to a maximum amplitude, the newly generated negative vortex starts to shed from the bilge keel. When the hull reverses its direction, a new positive vortex will start to occur from the tip of the bilge keels. As the roll motion progresses in time, a new vortex will be generated every half of an oscillation and a new cycle of vortex shedding will start. 

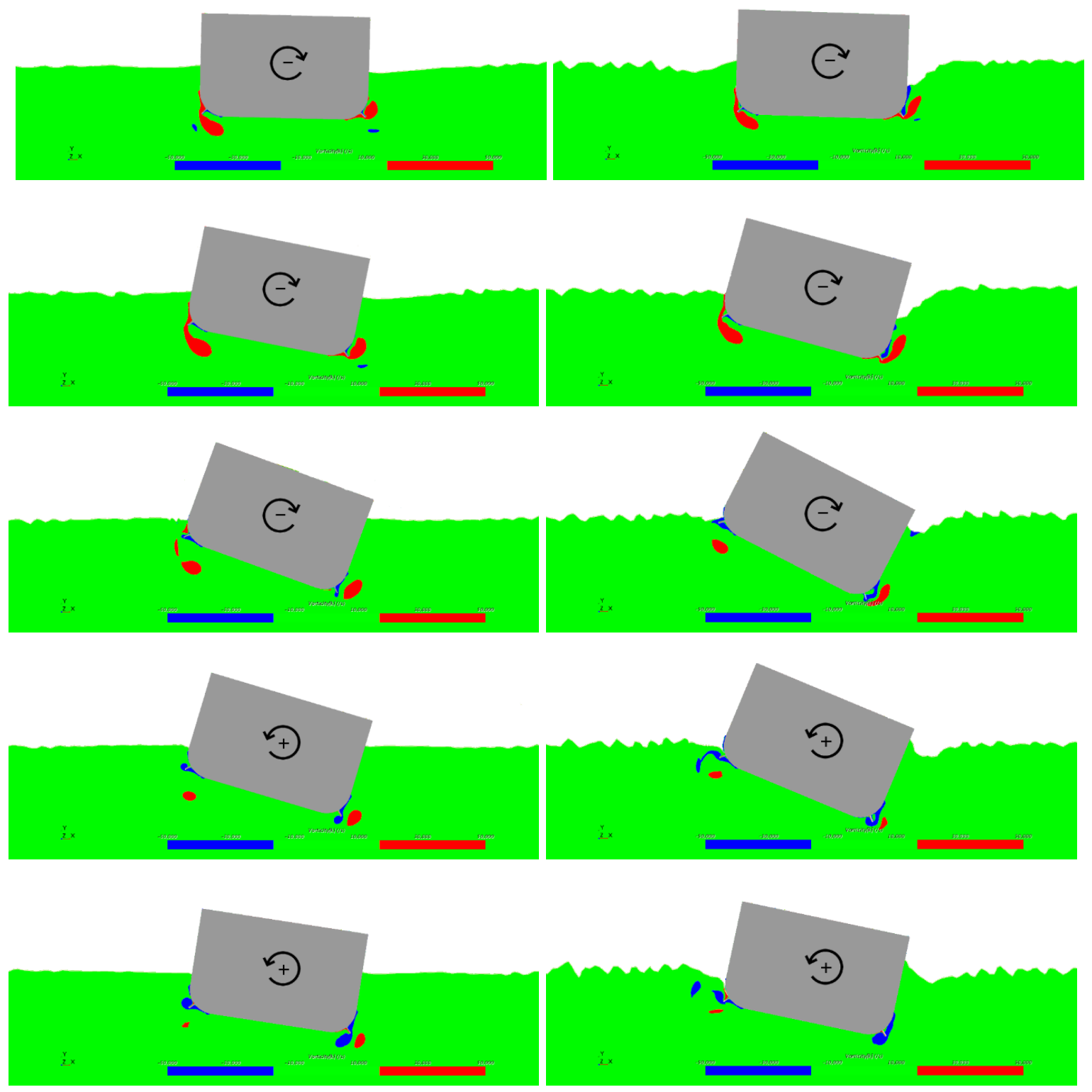

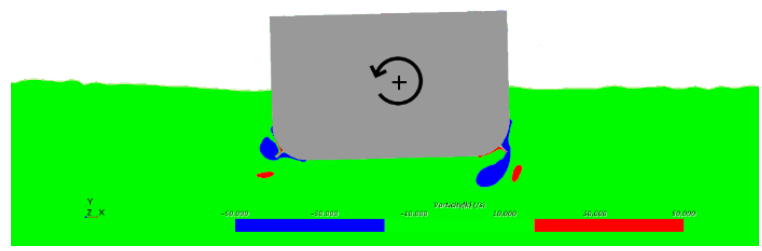

(a)

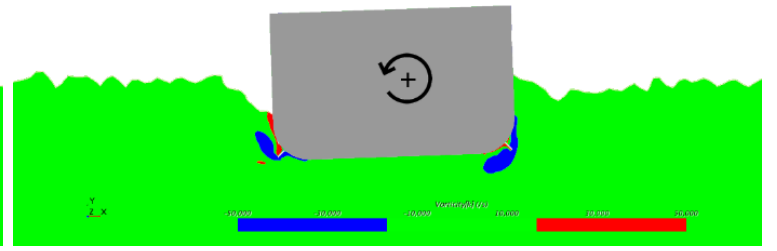

(b)

Fig. 12 Generation of vortices and vortex shedding around the hull form for (a) 20.0 deg. (b) 27.27 deg. roll amplitude

Fig. 12b. shows the vorticity contours around the bilge keels for $27.27 \mathrm{deg}$ roll amplitude where the bilge keel interacts with the free surface. As it is shown in the figure, the vortices start to shed earlier. After the hull reaches the maximum roll amplitude, the negative vortex starts to occur at the same point as for the $20 \mathrm{deg}$ roll amplitude case. However, the generation of the vortexes is affected by the presence of the free surface and the vortex starts to shed just after the maximum roll amplitude. This interaction with the free surface does not allow the vortices to grow. It can be seen that the size of the vortex for the $20 \mathrm{deg}$ amplitude motion is bigger than the large roll amplitude condition. This explains the decrease of bilge 
keel moment at large roll amplitude. The damping from the bilge keel decreases when the vortices become weaker. It has been also observed that the free surface disturbance is stronger for the $27.27 \mathrm{deg}$ amplitude motions as Himeno [5] cautioned that the bilge keel wave-making component cannot be neglected where bilge keel interacts with the free surface. It might be said that the wave-making damping increases when the bilge-keel component decreases at large roll amplitudes. Wave-making damping can be calculated by using the radiated wave amplitudes but it will be studied as a future work because the mesh around the free surface needs high quality to measure wave heights.

\section{Conclusion}

In this paper, a URANS numerical solver was used for the estimation of the effect of the roll amplitude on the roll damping. The unsteady flow around a forced rolling hull with bilge keels was simulated and the viscous-damping coefficient was computed for various roll amplitudes. The 1-DoF forced roll tests were also carried out to validate the numerical results. The generation of vortices around the hull during roll motion was visualized with numerical solver to show the interaction of the bilge-keel and free surface at large roll amplitudes. The URANS calculations and the experiments were done to validate the calculations. For the numerical uncertainties, an acceptable comparison error was calculated for the grid refinement and time step.

Numerical results showed good agreement at each roll angles with experimental results and several important observations were obtained from the numerical and experimental analysis. It has been shown that the total roll moment and roll moment due to the bilge keels are amplitude dependent. The total roll moment increased for each roll amplitude but the bilge keel roll moment decreased when the bilge keels approach the water/air interface due to the free surface interaction. The roll damping coefficients were obtained from calculated and measured roll moments. The total roll damping increased from small to moderate roll angles and it decreased at large roll amplitudes. The bilge keel interacted with the free surface at large roll amplitude and this interaction caused the decrease of the bilge keel damping contribution to the total roll damping. For small and moderate roll amplitudes, the relative contribution of the bilge keel to the total roll moment was over $60 \%$. However, near and above the free surface threshold, the bilge keel contribution to the total unit started to decrease due to the interaction of bilge-keel and free surface. Numerical solver was used to capturing the effect of vortex shedding and free surface interaction on the roll damping due to the large roll amplitudes. The flow around the hull with bilge keels was visualized and the generation of vortices was shown for different roll amplitudes and it was shown that vortices sheds from the bilge keel are proportional to the amplitude of roll motion. It was observed that the strength and core of the vortices grow until the free surface interaction starts which leads to increase of roll damping. The roll damping coefficient starts to decrease when the bilge keel come closer to the free surface because vortex generation and shedding is affected by the presence of the free surface. 


\section{REFERENCES}

[1] Choi, Y.M., Kwon, S.H., Park, J.H., Lee, S.B., Malenica, S., Jung, B.H., 2013, “Application of Multipole Expansions to Roll Damping," Brodogradnja. 64(2).

[2] Ikeda, Y., Komatsu, K., Himeno, Y., and Tanaka, N., 1977a, “On Roll Damping Force of Ship-Effect of Hull Surface Pressure Created by Bilge Keels,” J. Kansai Soc. Naval Architect Japan. 165.

[3] Ikeda, Y., Himeno, Y., and Tanaka, N., 1977b, "On Eddy Making Component of Roll Damping Force on Naked Hull,” J. Soc. Naval Architect Japan. 142.

[4] Ikeda, Y., Himeno, Y., and Tanaka, N., 1978, "Components of Roll Damping of Ship at Forward Speed," J. Soc. Naval Architect Japan. 143.

[5] Himeno, Y., 1981, "Prediction of Ship Roll Damping - State of Art," Department of Naval Architecture and Marine Engineering, University of Michigan, USA. Report No, 239.

[6] Kawahara, Y., Maekawa, K., and Ikeda Y., 2009, “A Simple Prediction Formula of Roll Damping of Conventional Cargo Ships on The Basis of Ikeda's Method and Its Limitation," Proceedings of the 10th International Conference on Stability of Ships and Ocean Vehicles. Sankt Petersburg, Russia, 387-398.

[7] Katayama, T., Yoshioka, Y., Kakinoki, T., and Ikeda, Y., 2010, "Some Topics for Estimation of BilgeKeel Component of Roll Damping," Proceedings of the 11th International Ship Stability Workshop. 225230.

[8] Ikeda, Y., and Katayama, T., 2000, "Roll Damping Prediction Method for a High-Speed Planing Craft," Proceedings of the 7th International Conference on Stability of Ship and Ocean Vehicles. STAB, 532541.

[9] Ikeda, Y., 2004, "Prediction Methods of Roll Damping of Ships and Their Application to Determine Optimum Stabilization Devices," Marine Technology. 41(2), 89-93.

[10] Yeung, R., and Ananthakrishnan, P., 1992, "Oscillation of a Floating Body in a Viscous Fluid," Journal of Engineering Mathematics. 26, 211-230. https://doi.org/10.1007/BF00043236

[11] Korpus, R., and Falzarano, J., 1997, "Prediction of Viscous Roll Damping by Unsteady Navier-Stokes Techniques," Journal of Offshore Mechanics and Arctic Engineering. 119, 108-113. https://doi.org/10.1115/1.2829050

[12] Yeung, R., Liao, W., and Roddier, D., 1998, "On Roll Hydrodynamics for Rectangular Cylinders," Proceedings of 8th International Offshore and Polar Engineering Conference. Montreal, Canada. 3, 44553.

[13] Sarkar, T., and Vassalos, D., 2000, “A RANS Based Technique for Simulation of the Flow near a Rolling Cylinder at the Free Surface," Journal of Marine Science and Technology. 5, 66-77. https://doi.org/10.1007/s007730070012

[14] Bassler, C.C., 2013, "Analysis and Modeling of Hydrodynamic Components for Ship Roll Motion in Heavy Weather," Ph.D. Thesis, Virginia Polytechnic Institute and State University.

[15] Avalos, G.O.G., Wanderley, J.B.V., and Fernandes, A.C., 2013, "Roll Damping Decay of a FPSO with Bilge Keel," Proceedings in ASME 32nd International Conference of Offshore Mechanics and Arctic Engineering. https://doi.org/10.1115/OMAE2013-10797

[16] Oliveira, A.C., and Fernandes, A.C., 2014, "The Nonlinear Roll Damping of a FPSO Hull," Journal of Offshore Mechanics and Arctic Engineering. 136(1), 1-10. https://doi.org/10.1115/1.4025870

[17] Van Kampen, M.J., 2015, "Bilge Keel Roll Damping Combining CFD and Local Velocities," Master of Science Thesis, Delft University of Technology.

[18] Irkal, M.A.R., Nallayarasu, S., and Bhattacharyya, S.K., 2016, "CFD Approach to Roll Damping of Ship with Bilge Keel with Experimental Validation," Applied Ocean Research. 55, 1-17. https://doi.org/10.1016/j.apor.2015.11.008

[19] Yıldız, B., Çakıcı, F., Katayama, T., and Yıımaz, H., 2016, "Urans Prediction of Roll Damping for a Ship Hull Section at Shallow Draft," Journal of Marine Science and Technology. 21:1, 48-56. https://doi.org/10.1007/s00773-015-0331-4

[20] Ommani, B., Kristiansen, T., and Faltinsen, O.M., 2016, "Simplified CFD Modeling for Bilge Keel Force and Hull Pressure Distribution on A Rotating Cylinder," Applied Ocean Research. 58, 253-265. https://doi.org/10.1016/j.apor.2016.04.010

[21] Yildiz, B., and Katayama, T., 2017, "Bilge Keel-Free Surface Interaction and Vortex Shedding Effect on Roll Damping," Journal of Marine Science and Technology 22. 432-446. https://doi.org/10.1007/s00773016-0423-9

[22] Roache, P. J., 1998, "Verification of Codes and Calculations," AIAA J. 36:5, 696-702. https://doi.org/10.2514/2.457

[23] Celik, I.B., Ghia, U., Roache, P.J, Christopher, F.J., Coleman, H., and Raad, P.E., 2008, "Procedure for Estimation and Reporting of Uncertainty due to Discretization in CFD Applications," Journal of Fluids Engineering, Trans. ASME. 130:7. 
[24] Stern, F., Wilson, R.V., Coleman H.W., and Paterson, E. G., 2001, "Comprehensive Approach to Verification and Validation of CFD Simulations - Part 1: Methodology and Procedures," Journal of Fluids Engineering. 23, 793-802. https://doi.org/10.1115/1.1412235

[25] Yıldız, B., Yurtseven, A., and Katayama, T., 2016, "Effect of Vortex Shedding and Free Surface Interaction on Roll Damping due to Large Amplitude Roll Motion," Proceeding of the 15th International Ship Stability Workshop.

Submitted: $\quad$ 27.05.2018. $\quad$ Burak Y1ld1z, buraky@yildiz.edu.tr

Accepted: $\quad$ 04.03.2019. $\quad 34349$, Besiktas, Istanbul, Turkey.

Bekir Şener (*corresponding author), bsener@yildiz.edu.tr

Yildiz Technical University, Naval Architecture and Maritime Faculty, 34349, Besiktas, Istanbul, Turkey.

Phone: +90 212 3832852, Fax: +90 2123833021

Ahmet Yurtseven, ahmety@yildiz.edu.tr

Yildiz Technical University, Naval Architecture and Maritime Faculty, 34349, Besiktas, Istanbul, Turkey.

Toru Katayama, katayama@marine.osakafu-u.ac.jp

Osaka Prefecture University, Graduate School of Engineering, Japan. 